\title{
Investigation of the adsorption characteristics of natural organic matter from typical Chinese surface waters onto alumina using quartz crystal microbalance with dissipation
}

\author{
Mingquan Yan ${ }^{\mathrm{a}, *}$, Dongsheng Wang ${ }^{\mathrm{b}, \mathrm{e}}$, Jiankun Xie ${ }^{\mathrm{b}}$, Chunxia Liu $^{\mathrm{c}}$, Jixia Cheng ${ }^{\mathrm{c}}$, \\ Christopher W.K. Chow ${ }^{\mathrm{b}, \mathrm{d}, \mathrm{e}}$, John van Leeuwen ${ }^{\mathrm{b}, \mathrm{e}}$ \\ a Department of Environmental Engineering, Peking University, The Key Laboratory of Water and Sediment Sciences, Ministry of Education, Beijing, 100871, China \\ b State Key Laboratory of Environmental Aquatic Chemistry, Research Center for Eco-Environmental Sciences, CAS, POB 2871, Beijing, 100085, China \\ ${ }^{c}$ College of Environmental Sciences and Engineering, Chang'an University, Xi'an, Shanxi, 710064, China \\ d Australian Water Quality Centre, SA Water, 250 Victoria Square, Adelaide, SA 5000, Australia \\ e SA Water Centre for Water Management and Reuse, School of Natural and Built Environments, University of South Australia, Mawson Lakes, South Australia 5095, Australia
}

\section{A R T I C L E I N F O}

\section{Article history:}

Received 8 December 2011

Received in revised form 29 January 2012

Accepted 15 February 2012

Available online 22 February 2012

\section{Keywords:}

Adsorption

Natural organic matter

QCM-D

Adsorbed layer

\begin{abstract}
A B S T R A C T
The adsorption of natural organic matter (NOM) from eight typical Chinese surface waters onto alumina was investigated using quartz crystal microbalance with dissipation monitoring (QCM-D). The adsorbed masses of NOM varied between $25 \mathrm{ng} \mathrm{cm}^{-2}$ and $64 \mathrm{ng} \mathrm{cm}^{-2}$, and these showed significant correlation with geographical location, and NOM character and concentrations. Adsorbed mass correlated with DOC concentration (slope $k=0.0676, R^{2}=0.61$ ) and hydrophobic acid $(\mathrm{HoA})$ and weakly hydrophobic acid (WHoA) $\left(k=0.0342\right.$ and $0.0183 ; R^{2}=0.49$ and 0.52 for HoA and WHoA, respectively) constituents present in the water samples. The process of adsorbed layer formation was investigated from changes in the $\Delta D / \Delta f$ ratio and viscosity of adsorbed layer with injected time. The adsorbed layer viscosity increased exponentially with injected time $\left(R^{2}>0.99\right)$ for most samples. Samples with low DOC concentration $\left(k=-1091.8, R^{2}=0.55\right)$ and low content of $\mathrm{HoA}$ and $\mathrm{WHoA}\left(k=-524.33\right.$ and $-322.76 ; R^{2}=0.41$ and 0.64 for HoA and WHoA, respectively), the slope of logarithm viscosity value is steeper, the property of adsorbed layer and NOM is more inconsistent. The QCM-D technique provides a method to view the process of complexation between NOM and coagulant, and can provide useful information to establish a quantitative calculation model of the coagulation process.
\end{abstract}

(C) 2012 Elsevier B.V. All rights reserved.

\section{Introduction}

The development of natural organic matter (NOM) removal prediction models and automatic coagulation process control has been reported by several researchers [1-5]. Edwards [1] and Kastl et al. [6] established semi-empirical, nonlinear mathematical models that allow prediction of total organic carbon (TOC) removal by coagulation in drinking water treatment. These models require input parameters of coagulant type and dose, coagulation $\mathrm{pH}$, raw water TOC concentrations or UV absorbance at $254 \mathrm{~nm}$. However, development of a theoretical model that enables prediction of NOM removal remains a difficult task partly because of the lack of knowledge of the interface process between NOM and hydrolyzed coagulants, such as alum.

To investigate the mechanism(s) and equilibrium parameters of adsorption of NOM onto aluminum oxide-hydroxide, researchers

\footnotetext{
* Corresponding author. Tel.: +86 1062755914 81; fax: +86 1062756526

E-mail address: yanmq@pku.edu.cn (M. Yan).
}

have employed many methods, including batch experiments, $\mathrm{Al}^{3+}$ and Fulvic acid (FA) titrations, acid-base titrations, IR techniques, etc. Browne and Driscoll [7], Jucker et al. [8] and Santhiya et al. [9] used batch or column isotherm experiments to determine the amounts of NOM adsorbed by comparing solution concentrations before and after adsorption. Based on zeta-potential and acid-base titration measurements, researchers hypothesized that electrostatic interactions and a ligand exchange process occur simultaneously when humic acids adsorb onto a pre-formed floc [7-9]. A correlation between removal efficiency and ionization of NOM functional groups was found, and the removal of NOM generally increased with a greater number of functional groups and with higher MW of NOM [10-14]. IR spectroscopy has also been used to qualitatively identify key functional groups and to obtain the structures of NOM interacting with coagulant hydrolysis product surfaces [12,15].

Batch experiments can introduce significant uncertainties when humic substances have low affinities to surfaces because of the inherent low sensitivity in the determination of the adsorbed mass. Due to the uncertainties in characterizing the surfaces that provide 
adsorption sites and with many unknown factors regarding natural organic adsorbates, few researchers have attempted to apply surface complexation models to experimental data. Quartz crystal microbalance with dissipation monitoring (QCM-D) is a useful technique for low-affinity cases, as QCM-D can quantify relatively low levels of adsorbed NOM ( $\left.\mathrm{ng} \mathrm{cm}^{-2}\right)$ in real-time monitoring [16]. Recently, the QCM-D technique was used in environmental studies to detect the adsorption of organic compounds such as dispersants $[17,18]$ and bacterial extracellular polysaccharides to $\mathrm{SiO}_{2}$ surface $[16,19]$ due to the high sensitivity of this technique.

In this paper, we report the application of the QCM-D technique to investigate the adsorption of NOM on alumina. Eight surface waters in China were selected based on their known qualities to provide waters with NOM of different concentrations and characteristics. Resin adsorption and high performance size exclusion chromatography (HPSEC) were used to characterize the NOM, and to investigate the effect of NOM characteristics on the adsorption process.

\section{Materials and methods}

\subsection{QCM-D experiments}

QCM-D technology has been previously described [16,17,20,21]. A QCM-D E1 system (Q-Sense AB, Gothenburg, Sweden) was used to examine the adsorption of NOM onto $\mathrm{Al}_{2} \mathrm{O}_{3}$ surfaces. QCM-D experiments were preformed with $5 \mathrm{MHz}$ AT-cut quartz sensor crystals with $\mathrm{Al}_{2} \mathrm{O}_{3}$-coated surfaces (Batch 081128-1). Prior to measuring, the crystal was cleaned by submerging it into an aqueous solution of a nonionic surfactant (Sabopal LM7). It was then rinsed in deionized water followed by ethanol and put in an ultrasonic bath for $10 \mathrm{~min}$. The crystal was rinsed again in deionized water, dried over flowing nitrogen gas, and then exposed to UV/ozone for $10 \mathrm{~min}$. The whole procedure was repeated once again, and the crystals were subsequently put in sterile containers for future use. The temperature of the measurement chamber was kept at $25 \pm 0.1^{\circ} \mathrm{C}$. A baseline was first established for deionized water, and then the sample was injected, the changes in frequency and dissipation upon adsorption at various overtones were monitored simultaneously throughout the experiment.

A commercial software program (Q-Tools, Q-Sense AB, Gothenburg, Sweden) developed for QCM-D was used [22,23]. For the Voigt Model, bulk density and bulk viscosity values were $1.0 \mathrm{~g} \mathrm{~cm}^{-3}$ and $0.001 \mathrm{~Pa}$ s, respectively. The adsorbed layer density was presumed to be $1.0 \mathrm{~g} \mathrm{~cm}^{-3}$.

\subsection{HPSEC}

The method of HPSEC was the same as reported by Wang et al. [24]. A Waters liquid chromatography system consisting of the following components was used for the MW analysis: Waters 2487 Dual k Absorbance Detector, Waters 1525 pump system. Separation was performed with a Shodex KW 802.5 column (Shoko Co., Japan). The mobile phase was deionized water buffered with $5 \mathrm{mM}$ phosphate to $\mathrm{pH} 6.8$, and $0.01 \mathrm{M} \mathrm{NaCl}$, filtered through a $0.22 \mu \mathrm{m}$ membrane, and then degassed for $30 \mathrm{~min}$. The flow rate was $0.8 \mathrm{~mL} \mathrm{~min}^{-1}$ and the injection volume was $200 \mu \mathrm{L}$. Calibration was performed using polystyrene sulfonate (PSS) standards (Polysciences, USA) of MWs 1.8, 4.2, 6.5, and $32 \mathrm{kDa}$ (Sigma-Aldrich, USA), prepared at $1 \mathrm{~g} \mathrm{~L}^{-1}$ concentration.

The MW profile was analyzed using a peak fitting software (Version 4, Systat Software Inc.) to resolve peak components and the peak area of each peak was used to provide quantitative characterization information $[24,25]$.

\subsection{Resin adsorption}

Amberlite XAD-8, and XAD-4 were used to fractionate NOM [26]. Water samples were pre-filtered using $0.45 \mu \mathrm{m}$ pore size filter membrane to remove particles, and then ran through an XAD-8 packed Column I. The hydrophobic base and neutral (HoB\&N) fractions were absorbed by the resin. Column I was then backwashed with $0.1 \mathrm{M} \mathrm{HCl}$ to release the hydrophobic base (HoB) fraction. The hydrophobic neutral $(\mathrm{HoN})$ fraction remained in the column. The $\mathrm{pH}$ of the Column I effluent was adjusted to 2 with $\mathrm{HCl}$ before reintroduction into Column I. The second effluent of Column I contained weakly hydrophobic and hydrophilic fractions. The TOC of the first effluent from Column I minus that of the second effluent gave the hydrophobic acid (HoA) fraction. The second effluent from Column I was introduced into the XAD-4 packed Column II. The TOC absorbed was the weakly hydrophobic acid (WHoA) fraction, whereas the TOC of the effluent was the hydrophilic (HiM) fraction. The columns were 3-cm-diameter and 30-cm-height glass chromatographic columns with PTFE caps. A constant flow rate of $100 \mathrm{~mL} \mathrm{~min}^{-1}$ through each column was maintained using peristaltic pumps.

\subsection{Analytical methods}

TOC was analyzed using a Phoenix 8000 system (TekmarDohrman Co. USA). Dissolved organic carbon (DOC) was analyzed after filtration through a $0.45 \mu \mathrm{m}$ membrane. $\mathrm{UV}_{254}$ was measured by a spectrophotometer (UV-vis 8500 , China) after filtration through a $0.45 \mu \mathrm{m}$ membrane. SUVA is calculated as $U_{254}$ divided by the $\mathrm{mg} \mathrm{L}^{-1}$ DOC concentration. Turbidity was measured using a $2100 \mathrm{~N}$ Turbidimeter (Hach, USA). Alkalinity was measured by standard methods [27]. pH was measured using a pHS-3C pH meter (Shanghai, China) calibrated daily using $\mathrm{pH}$ buffer solutions.

\section{Results and discussion}

\subsection{Source water characterization}

The eight surface waters used in this study were sourced from the Songhuajiang River, Yellow River, Yangtze River and Pear River. They are the four largest river systems running into Pacific Ocean, and are located from north to east in China. Two water samples were taken from each river system, one was from the main trunk river and the other was from a tributary or an associated reservoir. The geographic locations of the sources of water samples are shown in Fig. 1.

- Songhuajiang River (SHJ, sampled from Harbin) and Mopanshan Reservoir (MPS) are of the Songhuajiang river system, located in northeastern China (latitude $44.0^{\circ}-46.7^{\circ}$ ).

- Yellow River (YLW, sampled at Dongying City) and Herbei Reservoirs (HBR, ducted from reservoirs in the Hebei Province to Beijing and sampled at Beijing) are of the Yellow River system, located in northern China (latitude $37.5^{\circ}-41.0^{\circ}$ ).

- Yangtze River (YZR, sampled at Nantong) and Qiantangjiang River (QTJ, sampled at Xiaoshan) are of the Yangtze River system, located in the midland of China (latitude $28.9^{\circ}-32.6^{\circ}$ ).

- Beijiang River (BJR, sampled at Guangzhou) and Xihangdao Reservoir water (XHD, ducted from Xicun and Shimen reservoirs, sampled at Guangzhou) are of the Pear River system, located in southern China, (latitude $23.0^{\circ}-23.2^{\circ}$ ).

Water quality parameters for the eight water samples are shown in Table 1 . These samples had turbidities ranging from 1 to 85 NTU, alkalinities from 31 to $171 \mathrm{mg} / \mathrm{L}$, DOC concentrations from 
Table 1

Basic parameters of water quality for eight water samples.

\begin{tabular}{|c|c|c|c|c|c|c|c|}
\hline Sample & $\mathrm{pH}$ & Alkalinity $\left(\mathrm{mg} \mathrm{L}^{-1}\right)$ & Turbidity (NTU) & $\mathrm{DOC}\left(\mathrm{mg} \mathrm{L}^{-1}\right)$ & $\mathrm{UV}_{254}\left(\mathrm{~cm}^{-1}\right)$ & SUVA $\left(\mathrm{m}^{-1} \mathrm{mg}^{-1} \mathrm{~L}\right)$ & Location \\
\hline $\mathrm{SHJ}{ }^{\mathrm{a}}$ & 7.93 & 84 & 30 & 4.13 & 0.0978 & 2.36 & Northeastern \\
\hline $\mathrm{MPS}^{\mathrm{b}}$ & 7.46 & 31 & 0.75 & 4.37 & 0.1009 & 2.31 & \\
\hline YLW $^{\mathrm{a}}$ & 7.94 & 173 & 5 & 3.80 & 0.0532 & 1.40 & Northern \\
\hline $\mathrm{HBR}^{\mathrm{b}}$ & 8.04 & 120 & 1.9 & 2.14 & 0.0386 & 1.80 & \\
\hline $\mathrm{YZR}^{\mathrm{a}}$ & 7.88 & 94 & 45 & 2.11 & 0.0377 & 1.78 & Midland \\
\hline $\mathrm{QTJ}^{\mathrm{c}}$ & 7.73 & 44 & 8 & 1.83 & 0.0306 & 1.67 & \\
\hline $\mathrm{BJR}^{\mathrm{a}}$ & 7.31 & 78 & 6 & 1.35 & 0.0313 & 2.32 & Southern \\
\hline $\mathrm{XHD}^{\mathrm{c}}$ & 7.34 & 66 & 85 & 3.10 & 0.0876 & 2.82 & \\
\hline
\end{tabular}

a Trunk river.

b Reservoir.

c Branch river.

1.4 to $4.4 \mathrm{mg} / \mathrm{L}, \mathrm{UV}_{254}$ from 0.03 to $0.10 \mathrm{~cm}^{-1}$ and SUVA from 1.4 to $2.8 \mathrm{~m}^{-1} \mathrm{mg}^{-1} \mathrm{~L}$. Samples from MPS and HBR had lower turbidities than samples from other sources, and this could be due to the settling of particulate matter in waters of these reservoirs. Water samples from northern China, YLW and HBR had the highest alkalinities with HBR being slightly lower than YLW. The alkalinities of samples from tributary rivers or reservoirs were slightly lower than corresponding main rivers. This could be due to faster water flow in the main rivers with greater air interchange at the water surface. All eight samples had SUVA values below $4.0 \mathrm{~m}^{-1} \mathrm{mg}^{-1} \mathrm{~L}$, indicating these may be polluted to some degree and possibly by synthetic compounds. Paired samples from the Songhuajiang (SHJ \& MPS) and Pear (BJR \& XHD) River systems that have catchments that are well vegetated had higher SUVA. The samples from, SHJ \& MPS had the highest DOC and $\mathrm{UV}_{254}$ values. The samples from YLW \& HBR had moderate DOC concentrations and $\mathrm{UV}_{254}$ absorbance. Higher DOC, $\mathrm{UV}_{254}$, and lower SUVA of the YLW indicate that more contaminants entered Yellow river than HBR. Paired samples were collected from the YZR \& QTJ and BJR \& XHD locations in mid and southern China where the climate is subtropical (humid and with wet seasonal periods). Water resources are plentiful in these areas, though these can be polluted by regional sewage outfalls and discharge of other wastewaters due to increasingly intense urban and industrial development in the areas.

The characters (MW and polarity) of NOM from the eight water sources were investigated by HPSEC and resin fractionation. The MW profiles are shown as the relative size of the absorbance

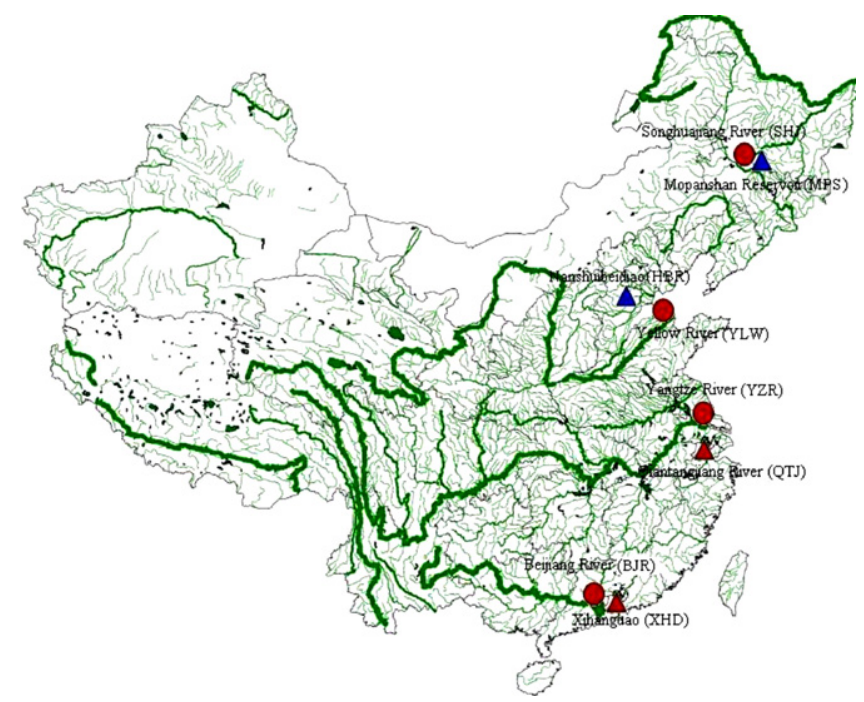

Fig. 1. The geographical locations of water samples ( $\bigcirc$ is trunk river, $\Delta$ is branch or reservoir; red is river, blue (MPS and HBR) is reservoir). (For interpretation of the references to color in this figure legend, the reader is referred to the web version of the article.).

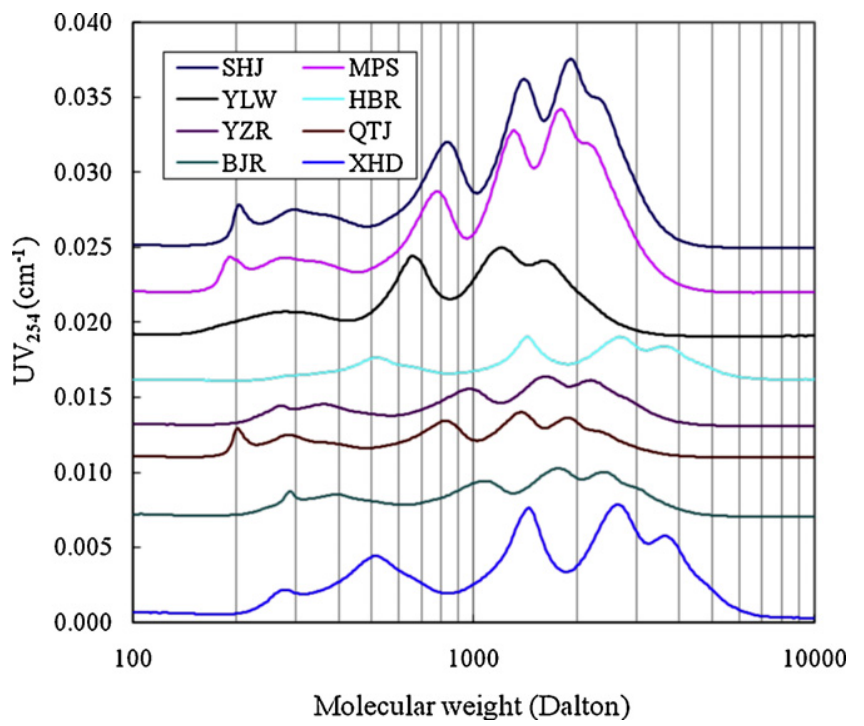

Fig. 2. The distributions of molecular weight for the water samples.

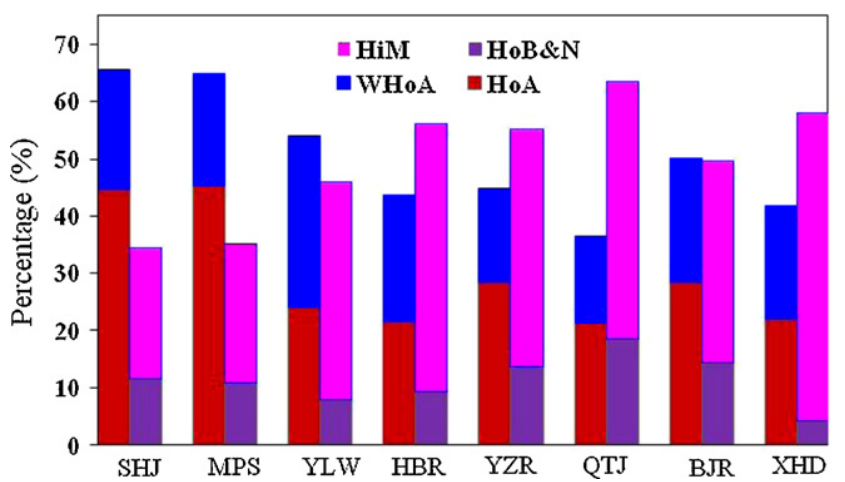

Fig. 3. The molecular polarity of NOMs in water samples, hydrophobic base and neutral $($ HoB\&N), hydrophobic acid (HoA), weakly hydrophobic acid (WHoA) and hydrophilic matters (HiM).

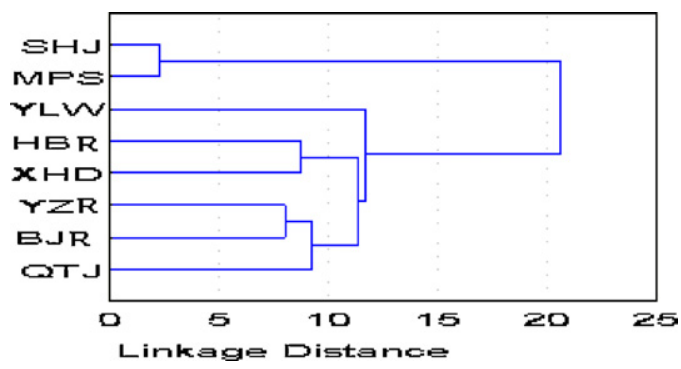

Fig. 4. The results of cluster analysis for the water samples based on NOM characteristics fractionated by resin absorption. 

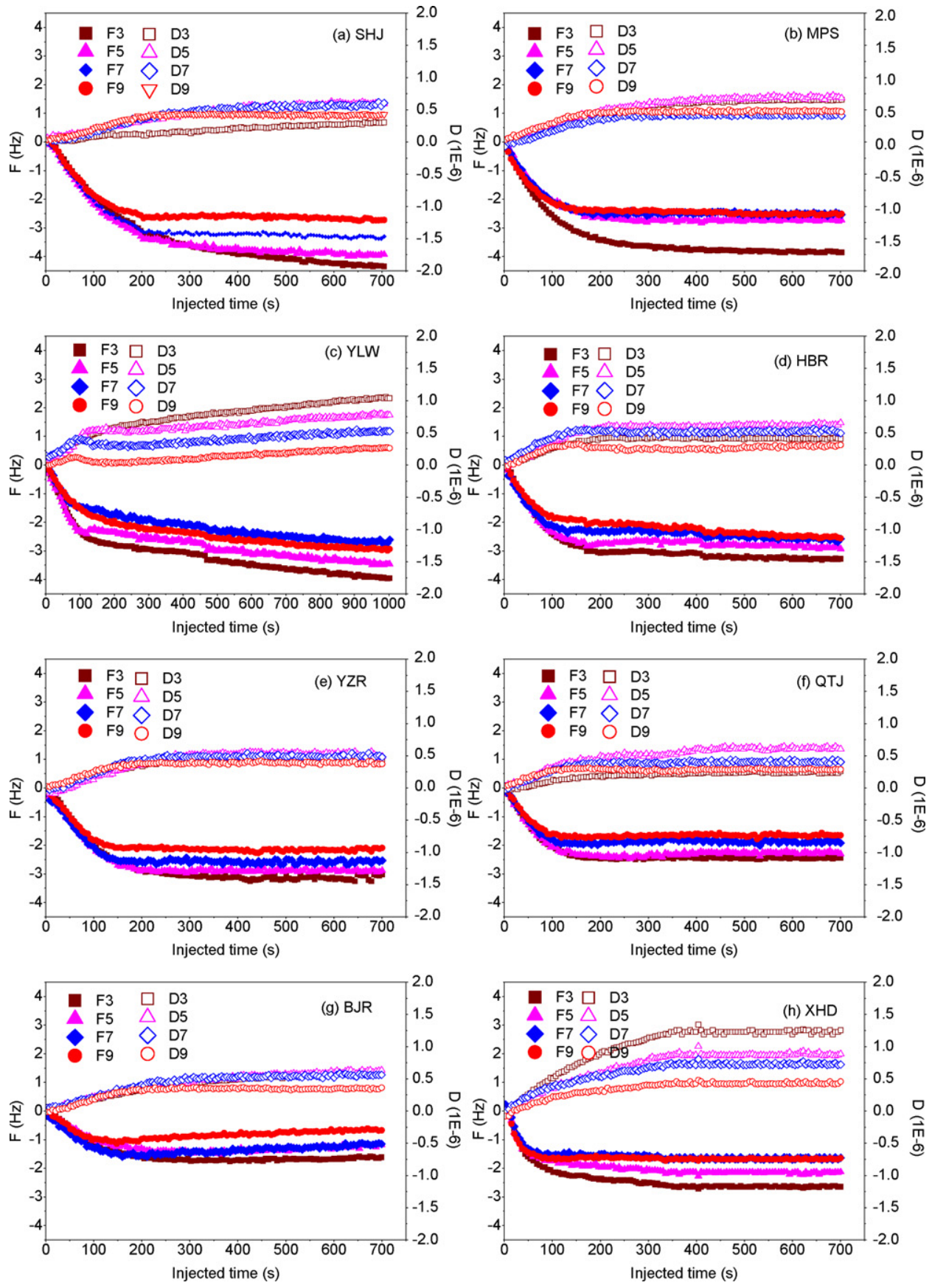

Fig. 5. Performances of NOM adsorption onto $\mathrm{Al}_{2} \mathrm{O}_{3}$ monitored by QCM-D for the water samples.

signal normalized with the DOC concentration, shown in Fig. 2. The MW profiles were analyzed further using peak fitting software, to resolve peak components based on statistically ideal fits using various peak shapes [24] and the results are provided in supporting information. The MW were highest in SHJ and MPS samples, with percentages of MW $>1 \mathrm{kDa}$ being up to more than $80 \%$. This may be due to relatively high humic substance content in the SHJ and MPS samples. In contrast QTJ and YLW had lower fractions of organics with MW $>1 \mathrm{kDa}$, where percentages of MW $>1 \mathrm{kDa}$ were only $45.6 \%$ and $57.9 \%$, respectively. The percentages of $\mathrm{MW}>1 \mathrm{kDa}$ in other four samples ranging from $71.2 \%$ to $74.3 \%$.

The results of resin fractionation of NOM are shown in Fig. 3. The data was analyzed using cluster analysis and the results are provided in Fig. 4. The resin fractionation results of SHJ and MPS are very similar, and contrast with the others. The percentages of the summations of the HoA and WHoA fractions in SHJ and MPS were the highest in all the water samples, and as high as 65\%. YZR and BJR are the two largest rivers in the mid and south of China, and resin fractionation results of NOM from samples from these sources were similar. Although QTJ is a tributary river, (located in the middle of China), the results of resin fraction of organics from this water are similar to those of YZR and BJR. Results of resin fractionation conducted on water samples collected from HBR and XHD are similar, even though XHD is located in southern China, and HBR is located in northern China. It shows that the molecular polarity of NOM is well correlated to its geographic location, and to the surrounding catchment.

\subsection{Adsorption features}

The adsorptions of NOMs onto alumina were measured by QCM$\mathrm{D}$ for the eight water samples, and the curves of $\Delta f$ and $\Delta D$ at 
Table 2

Results of NOM adsorption onto $\mathrm{Al}_{2} \mathrm{O}_{3}$ for the eight water samples calculated using the linear Sauerbrey relation and the Vigot model.

\begin{tabular}{|c|c|c|c|c|c|c|c|}
\hline \multirow[t]{2}{*}{ Sample } & \multicolumn{5}{|c|}{$\Delta m_{\text {Sauertery }}\left(\mathrm{ng} / \mathrm{cm}^{2}\right)$} & \multirow[t]{2}{*}{$D_{\mathrm{f}, \text { Voigt }}(\mathrm{nm})$} & \multirow[t]{2}{*}{$\Delta m_{\text {Voigt }}\left(\mathrm{ng} / \mathrm{cm}^{2}\right)$} \\
\hline & Average & $n=3$ & $n=5$ & $n=7$ & $n=9$ & & \\
\hline $\mathrm{SHJ}$ & 64 & 78 & 68 & 60 & 48 & 0.63 & 63 \\
\hline MPS & 57 & 68 & 60 & 50 & 48 & 0.56 & 56 \\
\hline YLW & 60 & 70 & 60 & 55 & 54 & 0.60 & 60 \\
\hline HBR & 49 & 59 & 50 & 45 & 40 & 0.50 & 50 \\
\hline YZR & 48 & 55 & 52 & 46 & 38 & 0.48 & 48 \\
\hline QTJ & 39 & 44 & 44 & 36 & 32 & 0.38 & 38 \\
\hline BJR & 25 & 30 & 26 & 26 & 18 & 0.25 & 25 \\
\hline XHD & 37 & 45 & 40 & 32 & 30 & 0.35 & 35 \\
\hline
\end{tabular}

four different overtones ( $n=3,5,7$, and 9) are given in Fig. 5a-h, respectively. To reduce noise, the value of $\Delta f$ and $\Delta D$ is presented as average value with about $5 \mathrm{~s}$ increment of injected time. With NOM injected into the QCM-D, $\Delta f$ decreased and $\Delta D$ increased from the baseline $[17,21,23]$. Near steady-states of $\Delta f$ and $\Delta D$ values for each water sample were obtained within 200-1000 s.

The masses of NOM adsorbed onto $\mathrm{Al}_{2} \mathrm{O}_{3}$ were calculated using the linear Sauerbrey relation at the four overtone values, and using the Vigot Model (Table 2). The Voigt Model mass values of NOM adsorption are in good agreement with the Sauerbrey mass average values. Generally, for a non-rigid and viscoelastic adsorbed layer, the Sauerbrey mass would be underestimated compared to a calculated mass based on the Voigt Model. It thus indicates that the layers of NOMs adsorbed onto $\mathrm{Al}_{2} \mathrm{O}_{3}$ are relatively inelastic and rigid, and the Sauerbrey equation should hold reasonably well for estimating NOM adsorption.

The adsorbed masses of NOMs onto $\mathrm{Al}_{2} \mathrm{O}_{3}$ vary between $64 \mathrm{ng} \mathrm{cm}^{-2}$ and $25 \mathrm{ng} \mathrm{cm}^{-2}$. Highest adsorbed mass values were for samples from northeastern China (SHJ and MPS) followed by samples from northern China (YLW and HBR), then YZR and QTJ located in midland of China and lowest adsorbed masses were for samples from southern China (BJR and XHD). The adsorbed masses of NOMs show a robust relationship with their geographical locations and latitude, which decreases from north to south in China.

The correlation between adsorbed masses of NOMs onto $\mathrm{Al}_{2} \mathrm{O}_{3}$ and water quality and NOM characteristics were studied and results are shown in Fig. 6 . These results show that the adsorbed mass of NOM correlates with DOC concentration $\left(k=0.0676, R^{2}=0.61\right)$. This finding is consistent with our previous research where HA adsorption and coagulation performance were studied [21]. The adsorbed

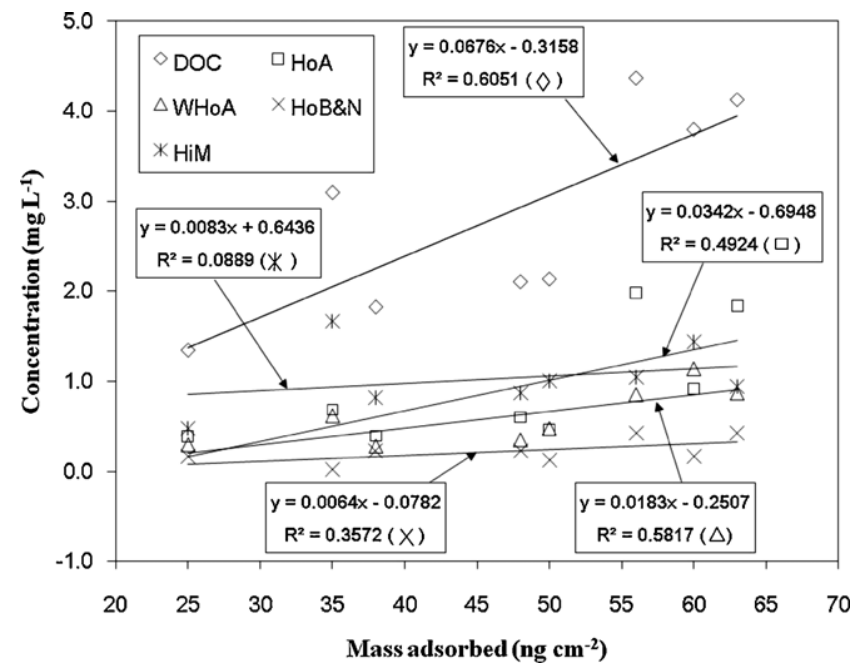

Fig. 6. Results of linear analysis for the correlation between adsorbed masses of NOM and molecular polarity. mass of NOM shows correlation with NOM molecular polarity also, where samples with higher content of HoA and WHoA, (and especially HoA) show higher adsorbed masses of NOM $(k=0.0342$ and $0.0183 ; R^{2}=0.49$ and 0.52 for HoA and WHoA, respectively). In contrast, no apparent relationship was found between the adsorbed mass of NOM and the content of HoB\&N and HiM. HoA and WHoA are mainly soil fulvic acids, comprising $<C_{9}$ aliphatic carboxylic acids, polyfunctional carboxylic acids, 1- and 2-ring aromatic carboxylic acids, 1- and 2-ring phenols [28]. These kinds of molecules can be adsorbed to alumina surface to a much larger extent. No significant correlation was found between adsorbed mass of NOM onto $\mathrm{Al}_{2} \mathrm{O}_{3}$ and other water quality parameters, such as $\mathrm{MW}, \mathrm{pH}$, alkalinity, turbidity, UV and SUVA.

\subsection{Adsorbed layer characteristics}

The $\Delta D / \Delta f$ ratio gives information on how much energy is dissipated by a material for a unit change in the resonance frequency. For example, a high $\Delta D / \Delta f$ ratio corresponds to a relatively nonrigid open structure whereas a low ratio corresponds to a rigid and more compact structure where the adsorbed mass induces relatively low-energy dissipation. Additionally, a change in the slope indicates coverage-induced structural changes in the adsorbed layer. A decrease in the slope is an indication that the layer has become more rigid due to the increased packing density $[22,23]$. The plots of the value $\Delta D / \Delta f$ against injected time at the third overtone for the eight water samples are shown in Fig. 7. The values of $\Delta D / \Delta f$ increase with injected time and reach a plateau

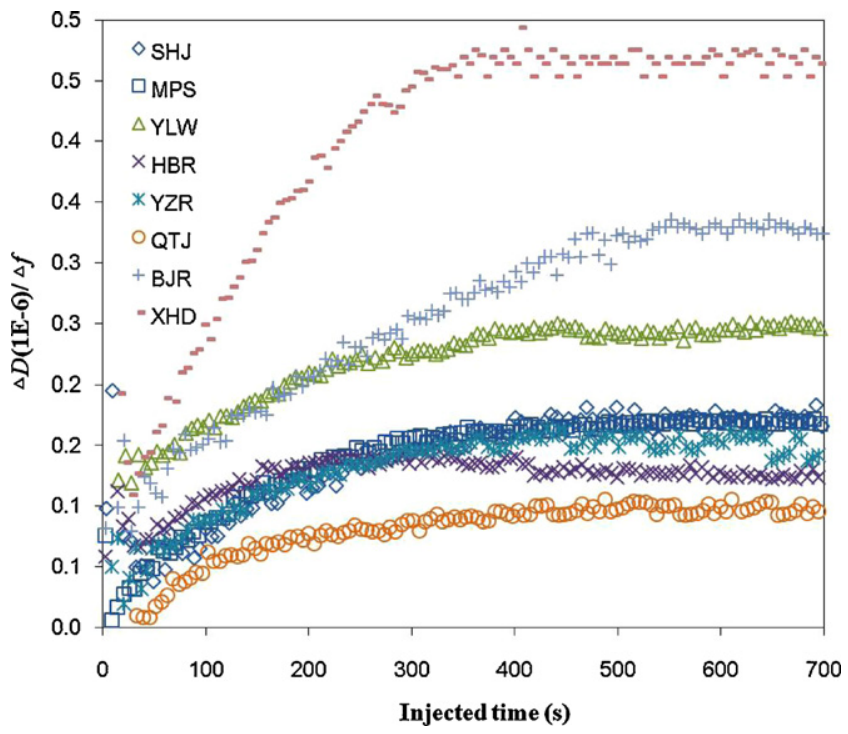

Fig. 7. Changes of dissipation vs frequency with injected time at the 3rd overtone for water samples. 

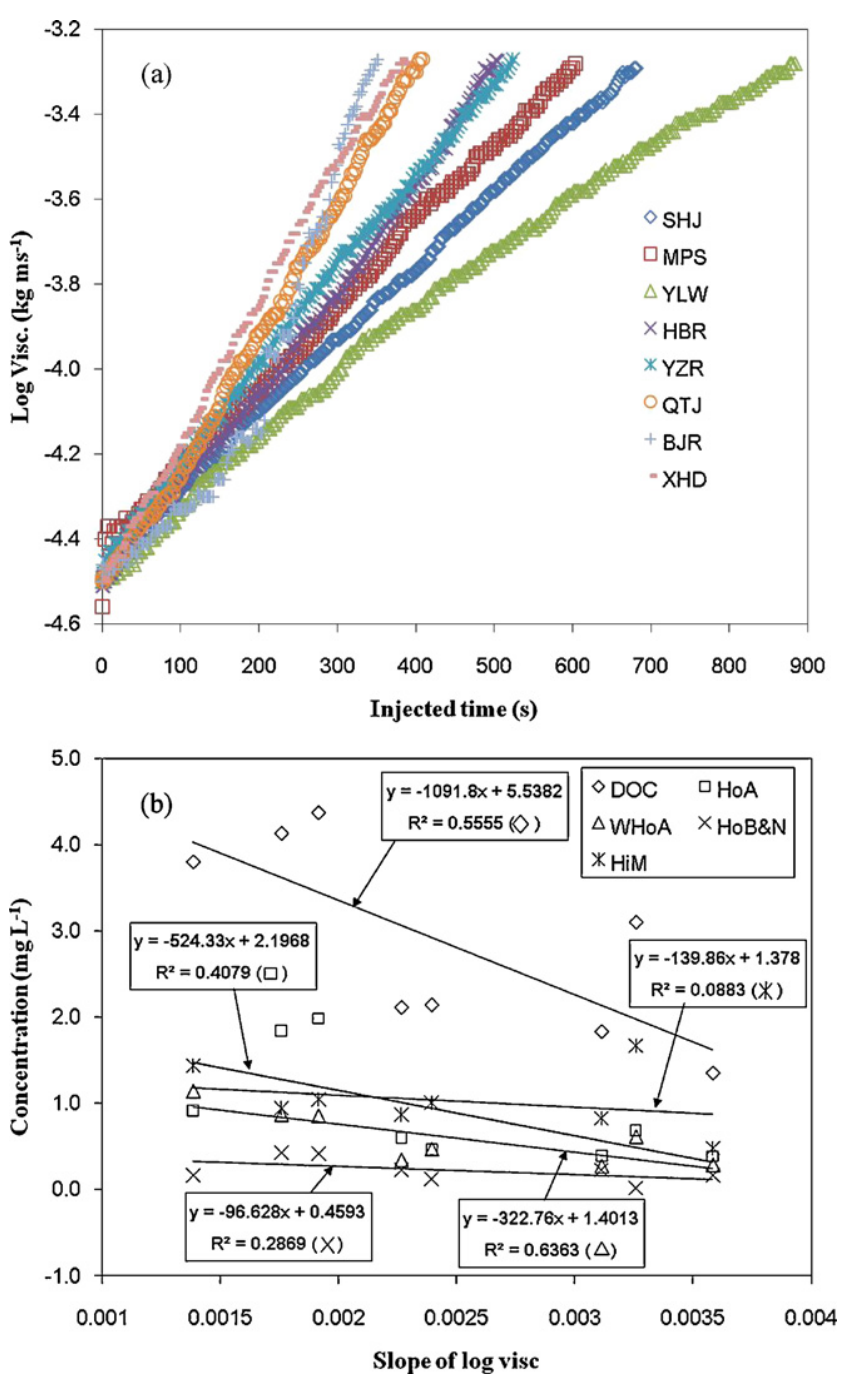

Fig. 8. The adsorbed layer viscosities for the water samples. (a)Changes of logarithm viscosity value vs injected time and (b) results of linear analysis for the correlation between slope of logarithm viscosity and molecular polarity.

after a particular time for each water sample. This indicates that the layer of adsorbed NOM becomes less rigid with injected time, more absorbable matter is adsorbed earlier, and the layer is more rigid.

The changes in the viscosity of the adsorbed layer with injected time can be calculated by commercial software such as Q-Tools. It was found that the viscosity increased approximately exponential with injected time. The logarithm viscosity value versus injected time increased linearly with injected time (Fig. 8(a) $R^{2}>0.99$ for the samples tested, except for BJR with $R^{2}=0.92$ ). The slope of logarithm viscosity reveals the process of adsorbed layer formation. When the slope is steeper (the viscosity increase is faster) the property of adsorbed NOM and adsorbed layer is more inconsistent. The correlations between the slope and water quality and with NOM characteristics were studied and the results are shown in Fig. 8(b). The slope correlated with DOC concentration $(k=-1091.8$, $\left.R^{2}=0.55\right)$, and the contents of HoA and WHoA $(k=-524.33$ and $-322.76 ; R^{2}=0.41$ and 0.64 , respectively). For sample with lower DOC concentration, and lower contents of HoA and WHoA, the slope of the logarithm of the viscosity value was steeper. Correlation between layer structure and the content of HoB\&N and HiM, MW, pH, alkalinity, turbidity, UV and SUVA were not found.

\section{Acknowledgements}

The authors are very grateful to the people who provided full support for this research. This research was also founded by CNSF 50808001 and the Doctoral Fund of Ministry of Education of China (RFDP 20090001120029).

\section{Appendix A. Supplementary data}

Supplementary data associated with this article can be found, in the online version, at doi:10.1016/j.jhazmat.2012.02.039.

\section{References}

[1] M. Edwards, Predicting DOC removal during enhanced coagulation, J. Am. Water Works Assoc. 89 (5) (1997) 78-89.

[2] J.K. Edzwald, J.E. Tobiason, Enhanced coagulation: US requirements and a broader view, Water Sci. Technol. 40 (9) (1999) 63-70.

[3] J.M. Duan, J. Gregory, Coagulation by hydrolysing metal salts, Adv. Colloid Interface Sci. 100-102 (2003) 475-502.

[4] G. Korshin, C.W.K. Chow, R. Fabris, M. Drikas, Absorbance spectroscopy-based examination of effects of coagulation on the reactivity of fractions of natural organic matter with varying apparent molecular weights, Water Res. 43 (2009) 1541-1548.

[5] N. Janot, P.E. Reiller, G.V. Korshin, M.F. Benedetti, Using spectrophotometric titrations to characterize humic acid reactivity at environmental concentrations, Environ. Sci. Technol. 44 (2010) 6782-6788.

[6] G. Kastl, I. Fisher, A. Sathasivan, J. van Leeuwen, Modelling DOC removal by enhanced coagulation, J. Am. Water Works Assoc. 96 (2) (2004) 79-89.

[7] B.A. Browne, C.T. Driscoll, pH dependent binding of aluminum by a fulvic acid, Environ. Sci. Technol. 27 (1993) 915-922.

[8] B.A. Jucker, H. Harms, S.J. Hug, A.J.B. Zehnder, Adsorption of bacterial surface polysaccharides on mineral oxides is mediated by hydrogen bonds, Colloids Surf., B 9 (1997) 331-343.

[9] D. Santhiya, S. Subramanian, K.A. Natarajan, Surface chemical studies on sphalerite and galena using extracellular polysaccharides isolated from Bacillus polymyxa, J. Colloid Interface Sci. 256 (2002) 237-248.

[10] J.A. Davis, R. Gloor, Adsorption of dissolved organics in lake water by aluminum oxide: effect of molecular weight, Environ. Sci. Technol. 15 (1981) 1223-1229.

[11] E. Lefebvre, B. Legube, Coagulation-floculat ion par le chlorure ferrique de quelques acides organique et phenols en solution aqueuse, Water Res. 27 (1993) 433-447.

[12] F. Julien, B. Gueroux, M. Mazet, Comparaison de l'élimination de molécules organiques par coagulation-floculation et par adsorption sur flocs d'hydroxyde métallique préformés, Water Res. 28 (1994) 2567-2574.

[13] P. Bose, D.A. Reckhow, Adsorption of natural organic matter on preformed aluminum hydroxide flocs, J. Environ. Eng. 124 (1998) 803-811.

[14] C.R. Evanko, D.A. Dzombak, Surface complexation modeling of organic acid sorption to goethite, J. Colloid Interface Sci. 214 (1999) 189-206.

[15] J. Omoike, A. Saxena, B. Song, B.B. Ward, T.J. Beveridge, S.C.B. Myneni, Elucidation of functional groups on gram-positive and gram-negative bacterial surfaces using infrared spectroscopy, Langmuir 20 (2004) 11433-11442.

[16] K.D. Kwon, H. Green, P. Bjoorn, J.D. Kubicki, Model bacterial extracellular polysaccharide adsorption onto silica and alumina: quartz crystal microbalance with dissipation monitoring of dextran adsorption, Environ. Sci. Technol. 40 (2006) 7739-7744

[17] L. Palmqvist, K. Holmberg, Dispersant adsorption and viscoelasticity of alumina suspensions measured by quartz crystal microbalance with dissipation monitoring and in situ dynamic rheology, Langmuir 24 (2008) 9989-9996.

[18] P.M. Karlsson, A.E.C. Palmqvist, K. Holmberg, Adsorption of sodium dodecyl sulfate and sodium dodecyl phosphate on aluminum, studied by QCM-D, XPS, and AAS, Langmuir 24 (2008) 13414-13419.

[19] M. Tong, H. Ma, W.P. Johnson, Funneling of flow into grain-to-grain contacts drives colloid-colloid aggregation in the presence of an energy barrier, Environ. Sci. Technol. 42 (2008) 2826-2832.

[20] M. Rodahl, F. Hook, A. Krozer, P. Brzezinski, B. Kasemo, Quartz-crystal microbalance setup for frequency and Q-factor measurements in gaseous and liquid environments, Rev. Sci. Instrum. 66 (1995) 3924-3930.

[21] M.Q. Yan, C.X. Liu, D.S. Wang, J.R. Ni, J.X. Cheng, Characterization of adsorption of humic acid onto alumina using quartz crystal microbalance with dissipation, Langmuir 27 (2011) 9860-9865.

[22] S.M. Notley, M. Eriksson, L. Wagberg, The influence on paper strength properties when building multilayers of weak polyelectrolytes onto wood fibres, J. Colloid Interface Sci. 292 (2005) 29-37.

[23] A.K. Dutta, G. Belfort, Adsorbed gels versus brushes: viscoelastic differences Langmuir 23 (2007) 3088-3094.

[24] D.S. Wang, L. Xing, J. Xie, C.W. Chow, Z. Xu, Y. Zhao, M. Drikas, Application of advanced characterization techniques to assess DOM treatability of micropolluted and un-polluted drinking source waters in China, Chemosphere 81 (2010) 39-45. 
[25] C.W.K. Chow, R. Fabris, J. van Leeuwen, D.S. Wang, M. Drikas, Assessing natural organic matter treatability using high performance size exclusion chromatography, Environ. Sci. Technol. 42 (2008) 6683-6689.

[26] M.Q. Yan, D.S. Wang, S.J. You, J.H. Qu, H.X. Tang, Enhanced coagulation in a typical NorthChina water plant, Water Res. 40 (2006) 3621-3627.
[27] A.E. Greenberg, L.S. Clesceri, A.D. Eaton (Eds.), Standard Methods for the Examination of Water and Wastewater, 19th ed., American Public Health Association, Washington, DC, 1995.

[28] J.I. Swietlik, Reactivity of natural organic matter fractions with chlorine dioxide and ozone, Water Res. 38 (2004) 547-558. 